\section{GENES DE RESISTENCIA A CARBAPENÉMICOS EN ENTEROBACTERIAS: ¿CONOCEMOS REALMENTE LA PREVALENCIA DE CARBAPENEMASAS EN PERÚ?}

\author{
CARBAPENEMIC-RESISTANT GENES IN \\ ENTEROBACTERIA: DO WE REALLY KNOW \\ THE PREVALENCE OF CARBAPENEMASES IN \\ PERU?
}

Jose A. Gonzales-Zamora ${ }^{1, a}$

\begin{abstract}
Sr. Editor. He leído con gran interés la reciente publicación de Sacsaquispe-Contreras et al. sobre la identificación de genes de resistencia a carbapenémicos en enterobacterias de hospitales de Perú (1). Los autores realizaron un estudio descriptivo observacional en el cual analizaron cepas bacterianas productoras de carbapenemasas por medio de Reacción en Cadena de la Polimerasa (PCR) convencional. El estudio incluyó doce hospitales pertenecientes al Ministerio de Salud, Seguro Social y Fuerzas Armadas desde el 2013 al 2017. Según la metodología descrita por los autores, la resistencia a carbapenémicos se determinó inicialmente mediante el método de disco de difusión y el método de tira de gradiente (E-test), para lo cual utilizaron meropenem e imipenem. Sin embargo, se debe tener en cuenta que la resistencia a carbapenémicos es variable y no afecta de forma igualitaria a todos los antibióticos de esta clase; sobre todo en carbapenemasas tipo OXA, los cuales producen una hidrólisis lenta y parcial de carbapenems, siendo el más susceptible a hidrólisis el Ertapenem. Por esta razón, se recomienda utilizar Ertapenem para el tamizaje de carbapenemasas, con lo cual se logra una mayor sensibilidad en esta etapa inicial (2).
\end{abstract}

Con relación al método fenotípico para detección de carbapenemasas, los autores mencionan la utilización del Test de Hodge hasta el 2014 y luego el uso de métodos cromogénicos y de disco con ácido fenilborónico y ácido etilendiaminotetraacético. Según los resultados mostrados,

\footnotetext{
Division of Infectious Diseases, Department of Medicine. University of Miami, Miller School of Medicine. Miami, Florida. EE. UU.

aédico cirujano

Recibido: 09/09/2018 Aprobado: 12/09/2018 En línea: 21/12/2018
}

Citar como: Gonzales-Zamora JA. Genes de resistencia a carbapenémicos en enterobacterias: ¿Conocemos realmente la prevalencia de carbapenemasas en Perú?. Rev Peru Med Exp Salud Publica. 2018;35(4):707-8.doi:10.17843/ rpmesp.2018.354.3918. todas las cepas analizadas por estos métodos fenotípicos mostraron genes de resistencia a carbapenems en el análisis molecular por PCR, lo cual sugiere un alto valor predictivo positivo de los métodos fenotípicos señalados; sin embargo, esto no siempre se cumple en la práctica diaria. Cabe mencionar que el test de Hodge tiene una sensibilidad de $95 \%$ y una especificidad de $91 \%$, pudiendo dar falsos positivos en casos de mecanismos de resistencia combinados diferentes de carbapenemasas, por ejemplo, en cepas productoras de cefalosporinasas (Amp-C o BLEE) asociado con mutaciones de porinas ${ }^{(3)}$. Llama la atención que en el estudio realizado por SacsaquispeContreras et al. no se detectaron casos de falsos positivos, sobre todo durante el periodo del 2013 al 2014, en el cual se utilizó solamente el test modificado de Hodge para la identificación fenotípica de carbapenemasas.

Otro punto a resaltar es el uso de PCR convencional para detectar los genes bla KPC, NDM, VIM e IMP, lo cual corresponde a carbapenemasas tipo $\mathrm{A}$ y $\mathrm{B}$, siendo estas las más frecuentes a nivel mundial. Sin embargo, las carbapenemasas tipo $D$ producidas por el gen OXA son relativamente frecuentes en Europa y en países mediterráneos, sobre todo en Turquía en donde la frecuencia de carbapenemasas tipo OXA-48 llega al $92 \%{ }^{(4)}$. En Sudamérica también se ha descrito reportes de Enterobacteriaceae productoras de enzimas tipo OXA, particularmente en Argentina, Brasil y Colombia ${ }^{(5,6)}$.

En el Perú, el estudio de Sacsaquispe-Contreras et al. es la primera evidencia de la distribución de genes de resistencia a carbapenems en hospitales de Lima, en donde se observa una predominancia de genes productores de metalo- $\beta$-lactamasas, lamentablemente no se evaluó la presencia de carbapenemasas tipo OXA, por lo que la prevalencia de estas últimas en Enterobacteriaceae es a la fecha desconocida.

\section{Fuentes de Financiamiento: Autofinanciado}

Conflictos de Interés: El autor declara no tener conflictos de interés.

\section{REFERENCIAS BIBLIOGRÁFICAS}

1. Sacsaquispe-Contreras R, Bailón-Calderón H. Identification of carbapenem-resistant genes in enterobacteria from Peruvian hospitals, 2013-2017. Rev Peru Med Exp Salud Publica. 2018; 35(2):259-264.

2. Poirel L, Potron A, Nordmann P. OXA-48-like carbapenemases: the phantom menace. J Antimicrob Chemother. 2012; 67(7):1597-606.

3. Anderson KF, Lonsway DR, Rasheed JK, Biddle J, Jensen B, McDougal LK, Carey RB, Thompson A, Stocker S, Limbago B, Patel JB. Evaluation of methods to identify the Klebsiella pneumoniae carbapenemase in Enterobacteriaceae. J Clin Microbiol. 2007; 45(8):2723-5. 
4. Van Duin D, Doi Y. The global epidemiology of carbapenemase-producing Enterobacteriaceae. Virulence. 2017; 8(4):460469.

5. Ocampo AM, Chen L, Cienfuegos AV, Roncancio G, Chavda KD, Kreiswirth BN, Jiménez JN. A Two-Year Surveillance in Five Colombian Tertiary Care Hospitals Reveals High Frequency of Non-CG258 Clones of Carbapenem-Resistant Klebsiella pneumoniae with Distinct Clinical Characteristics. Antimicrob Agents Chemother. 2015; 60(1):332-42.

6. Pereira PS, Borghi M, de Araújo CF, Aires CA, Oliveira JC, Asensi MD, Carvalho-Assef AP. Clonal Dissemination of OXA-370-Producing Klebsiella pneumoniae in Rio de Janeiro, Brazil. Antimicrob Agents Chemother. 2015; 59(8):4453-6.

Correspondencia: Jose A. Gonzales-Zamora

Dirección: 1120 NW 14th Street, Suite 863B. Miami, Fl 33136. EE.UU.

Teléfono: (001) 706-284-3510

Correo electrónico:jxg1416@med.miami.edu

\section{SOBRESTIMACIÓN DE ALERGIA ALIMENTARIA REPORTADA POR PADRES EN UN CENTRO PERUANO DE ALERGIA, ASMA E INMUNOLOGÍA}

\section{OVERESTIMATION OF FOOD ALLERGIES REPORTED BY PARENTS IN A PERUVIAN ALLERGY, ASTHMA, AND IMMUNOLOGY CENTER}

\section{Daniel Mendoza-Quispe ${ }^{1,2, a}$, Liliana Alvarez ${ }^{1,2, a}$, César A. Galván ${ }^{3,4, b}$}

Sr. Editor. La alergia alimentaria $(\mathrm{AA})$ es una reacción adversa perjudicial de origen inmunológico. Afecta al 2-4 \% de la población mundial, al 6-8\% de niños menores de un año, ysu prevalencia sigue incrementándose significativamente desde las últimas décadas ${ }^{(1)}$. La búsqueda del término «alergia» en la base Scielo Perú (www.scielo.org.pe) muestra doce resultados, y sólo uno se relaciona con AA. La prevalencia y los alimentos causales varían entre países, el manejo está

Facultad de Medicina, Universidad Nacional Mayor de San Marcos. Lima, Perú. Asociación para el desarrollo de la investigación en Ciencias de la Salud. Lima, Perú.

3 Centro de Referencia Nacional de Alergia, Asma e Inmunología. Instituto Nacional de Salud del Niño. Lima, Perú.

4 Sociedad Peruana de Inmunología. Lima, Perú.

a Médico cirujano; ${ }^{b}$ médico especialista en Alergología e Inmunología Clínica Recibido:26/06/2018 Aprobado:28/11/2018 En línea: 21/12/2018

Citar como: Mendoza-Quispe D, Alvarez L, Galván CA. Sobrestimación de alergia alimentaria reportada por padres en un centro peruano de alergia, asma e inmunología. Rev Peru Med Exp Salud Publica. 2018;35(4):708-10. doi: 10.17843/rpmesp.2018.354.3763. centrado en la restricción dietética del alimento causal (2). Un diagnóstico equivocado de AA, del que frecuentemente participan los padres, conduciría a una innecesaria restricción dietética, que podría afectar el desarrollo nutricional y psicológico del niño ${ }^{(2,3)}$. Por ello, el objetivo del estudio fue evaluar la estimación de AA reportada por padres asistentes a un centro de alergia, asma e inmunología.

Desde setiembre de 2016 a enero de 2018 aplicamos una encuesta semiestructurada a padres de 328 pacientes menores de 18 años, que acudieron por primera vez a consulta ambulatoria al Centro de Alergia, Asma e Inmunología del Instituto Nacional de Salud del Niño ubicado en Lima. Los pacientes fueron evaluados por un médico alergólogo e inmunólogo clínico (anamnesis, examen físico y pruebas de alergia, en caso de ser necesarias) para determinar su diagnóstico definitivo. Se obtuvo el consentimiento informado verbal de los padres. Los datos fueron analizados de forma descriptiva usando el programa estadístico SPSS versión $24 \circledast$.

De 328 pacientes evaluados, el 59,8 \% fueron varones, el $27,1 \%$ tenía entre 0-2 años, el 28,4 \% tenía entre 3-5 años, y el $44,5 \%$ tenía entre 6-18 años. Asimismo, el 40,9 \% (134/328) de padres refirió que su hijo era alérgico a algún alimento (cítricos, leche y/o derivados, y alimentos con preservantes, entre los más frecuentes). Luego de ser evaluados sólo se confirmaron tres casos $(0,9 \%, 3 / 328)$, todos alérgicos a la proteína de leche de vaca. La manifestación que los padres más frecuentemente asociaron a AA fueron ronchas, tos y prurigo. El 57,5 \% (77/134) refirió que el diagnóstico le había sido dado por un médico. El 48,5 \% (159/328) refirió que alguna vez un médico le recomendó restringir algún alimento por sospecha de AA (Tabla 1).

Nuestro hallazgo es mayor a lo reportado por Ontiveros et al. quienes encuestaron a 1049 padres de niños mexicanos, además el 5,5\% respondió que su hijo tuvo alguna vez $A A$, y el 4,9 \% refirió que un médico alguna vez les dijo que su hijo tenía $A A^{(2)}$. Un metaanálisis europeo encontró una prevalencia de 5,9\% de AA cuando esta fue medida por autoreporte de los padres y 0,9\% cuando la AA era diagnosticada por test de provocación oral ${ }^{(1)(3)}$.

La mayoría de reacciones alérgicas son debidas a pocos alimentos como el maní, nueces, huevo, leche, pescado y mariscos ${ }^{(4)}$. Sin embargo las creencias pueden variar entre países, padres mexicanos reportaron que la leche, camarones y otros mariscos pueden causar alergia; padres noruegos reportan que las frutas, chocolate, nueces ${ }^{(4)}$ pueden causar alergia. En nuestra muestra encontramos la creencia de que los cítricos pueden causar mayoritariamente alergias; aunque se ha identificado sensibilización a cítricos, generalmente por reacción cruzada con proteínas homólogas a las del polen, la alergia es raramente observada ${ }^{(5)}$. 